\title{
Body Image Among 22 Persons with Acquired and Congenital Severe Mobility Impairment
}

\author{
R. Stensman, MD \\ Assistant Chief Physician, Department of Rehabilitation Medicine, Uppsala \\ University, Akademiska sjukhuset S-75185 Uppsala, Sweden.
}

\begin{abstract}
Summary
Interviews concerning body image were conducted with 10 persons with tetraplegia due to traumatic spinal cord injury and 12 persons with cerebral palsy. They all needed a wheelchair and daily assistance from another person. Their satisfaction/dissatisfaction with their body in different situations was reported on a visual analogue scale. The body size as estimated on a Body Puzzle was compared with true measurements. The body mass index of the 22 persons was calculated. These results showed only slight differences between the groups of persons with acquired and congenital motor impairment and did not differ from the results in a reference group. Information was obtained about different experiences of the interviewed persons, e.g. those from the viewpoint of a wheelchair user, lack of body language and moving about in dreams. In general, the adjustments made to the problems concerning body image by the persons with severe mobility impairment were successful. This finding is important in the light of the efforts among persons with severe mobility impairment to reach equality and 'a normal life'. Key words: Spinal cord injuries; Tetraplegia; Cerebral palsy; Body image; Psychological adaptation.
\end{abstract}

Two common causes of severe mobility impairment among people less than 50 years of age are traumatic spinal cord injury ( $\mathrm{SCI}$ ) and cerebral palsy (CP). These conditions imply loss of different physical functions and sometimes the need for daily assistance from another person and daily need of a wheelchair. Besides loss of functions, a person who has suffered a SCI may have problems with spasticity, pain, contractures, micturition and defaecation, loss of sensation, pressure sores, oedema and some loss of sexual function. Persons with CP might have involuntary movements, contractures, slobbering and dysarthria in addition to motor functional losses. To what extent do these acquired or congenital disabilities influence the person's body image?

Schilder (1935) defines body image as 'the picture of our own body which we form in our mind, that is to say the way the body appears to ourselves'. The 
term body image and related terms have been discussed by many authors, e.g. Fisher and Cleveland (1958) and van der Velde (1985).

In this study body image is defined as a psychological experience of the appearance of the body, its adequacy, and its external expression of the person's personality. Of importance in this context is also body language, the 'wheelchair level', choice of clothes, moving about in dreams, and attitudes of other persons.

The concept of body image has been applied to a wide range of pathological conditions within the fields of neurology, orthopaedics and psychiatry. Among the studies of somatic conditions, most have concerned the phantom sensation of an amputated limb and denial of the paralysed body parts by a person with damage to the non-dominant cerebral hemisphere.

Most studies concerning body image among persons with spinal cord injury have dealt with neurological aspects. Bors (1951) describes the phantom sensations of 50 patients with spinal cord injuries at various levels, of 7 patients with a combination of damage to the spinal cord and various amputations, and of 12 patients following chordotomy. Evans (1962) presents 7 patients with complete paraplegia (none with traumatic SCI) and their subjective sensations referred to their legs. Conomy (1973) describes body image distortions experienced by 18 persons with traumatic SCI.

Other reports describe a more psychological approach to body image among persons with SCI. Wachs and Zaks (1960) administered the Draw-A-Person test to two groups of persons-one group of 30 men with traumatic SCI and a control group of 30 men with chronic disease. The groups were comparable regarding average age and education. These subjects made a total of 60 drawings of the human form, which were analysed independently by two psychologists for abnormalities. Of the 30 most 'pathological' drawings an equal number had been drawn by the SCI and control groups. An analysis of 24 variables within these drawings revealed few differences between the two groups.

Arnhoff and Mehl (1963) hypothesised that confinement to a wheelchair for a prolonged period of time results in deterioration of the body image. A group of 18 male paraplegics was compared with a group of 20 non-paraplegics regarding estimated shoulder width, actual shoulder width and wheelchair width. The estimations of both the shoulder and the wheelchair widths made by the paraplegic group were higher than the actual widths, while the control group estimated the wheelchair width to be significantly lower than the actual one.

Mitchell (1970) investigated the Barrier Score (based on Rorschach responses) as a predictor of the level of adjustment to stress made by 48 male paraplegics and 48 male quadriplegics. Statistically significant differences in the Barrier score were found between the paraplegic high and low adjustment groups, but none was found between the corresponding quadriplegic groups. Rosillo and Fogel (1971) found only a few significant correlations between measures of body image (rated by the interviewers) and improvement in rehabilitation in their study of 110 physically disabled patients $\left(25^{\circ}{ }_{0}\right.$ of whom had SCI $)$.

A valuable review of the literature on this topic has been presented by Trieschmann (1980). Thus, in these early studies, although the occurrence of well-known pathological sensations below the lesion was found, the psychological findings were not clear-cut. Further studies appeared to be motivated, with more direct questions concerning individual experience. 
The aim of this study was to investigate differences in body image among persons with tetraplegia caused by SCI and cerebral palsy, and among nondisabled persons, and to analyse the experiences of the changed body.

\section{Patients and methods}

Eleven persons with tetraplegia caused by SCI, aged 25 to 55 years, in the municipality of Uppsala (154,900 inhabitants) were contacted. These persons were known either from earlier investigations based on various registers (Stensman, 1985) or as patients at the only rehabilitation clinic in Uppsala, and they probably represented all persons with tetraplegia caused by traumatic SCI in this municipality. In the same way 14 persons with CP were contacted. One person in the former and two in the latter group did not wish to be interviewed. Thus, interviews were conducted with 22 persons. Their age, sex, civil status and vocational status are presented in Table I.

The 10 persons with traumatic SCI had had their impairment for 5 to 24 years (mean 12.4 years). The ages at the time of injury were 18 to 41 years (mean 26.4 years) and the injuries were caused by diving (4), car accidents (4), horseback riding (1) and bicycling (1). Seven of the 10 persons with tetraplegia had no function in their triceps muscles and their intrinsic hand muscles. Nine of them had no motor activity and no or only patchy sensibility below the lesion. One man had some mobility below the level of the lesion, but needed daily assistance from another person and used a wheelchair daily. Five persons with SCI suffered from considerable pain.

Among the 12 persons with CP, 10 had athetosis, 4 had severe dysarthria and 2 persons slobbered. The 22 interviewed persons had no other severe disability (e.g. blindness, dementia, very severe dysarthria).

All 22 subjects needed daily assistance according to Katz' ADL Index (Activities of Daily Living) (Katz, 1963). This index is based on an evaluation of the functional independence or dependence of patients in bathing, dressing, going to the toilet, transfer, continence and feeding. Rated on this index, 6 of the 10 persons with SCI belonged to groups E, F or G (most dependent) and this was the case for 10 of the 12 persons in the CP group.

Forty three non-disabled persons (23 males, 20 females) of corresponding ages ( 25 to 45 years), working at a large hospital served as a reference group. They were chosen at random.

All 22 subjects were interviewed by the author. The interviews were partly structured. They concerned various experiences from the disabled body. The degree of satisfaction/dissatisfaction of the subject with the body in different situations was rated on visual analogue scales. Half of the 22 subjects needed help to mark on the $100 \mathrm{~mm}$ long line.

With a test: Body Puzzle, developed by Elisabet Berg, the ratios between estimated and real body size were measured. The Body Puzzle is composed of nine homunculi (all $20 \mathrm{~cm}$ high) of different widths (Fig. 1). They had each been divided into nine parts (head and neck, upper and lower part of the trunk, arms, thighs and lower part of the legs). The interviewed person, who had 81 parts to choose between, was asked to present a model representing his or her conceived body size. This estimated size was compared with measurements 
Table I The 22 interviewed persons and some demographic data. SCI = traumatic spinal cord injury with tetraplegia. $\mathrm{CP}=$ cerebral palsy

\begin{tabular}{llccccc}
\hline & & \multicolumn{2}{c}{ Age } & & \\
\cline { 2 - 6 } Diagnosis & $\mathrm{n}$ & Range & Mean & Male/Female & Single & Employed \\
\hline SCI & 10 & $28-53$ & $38 \cdot 8$ & $8 / 2$ & 6 & 6 \\
CP & 12 & $28-55$ & $41 \cdot 6$ & $5 / 7$ & 8 & 5 \\
\hline
\end{tabular}

Table II Body image experienced in different situations by persons with and without severe motor impairment, marked on a visual analogue scale (score 0-100, between 'extremely negative' and 'extremely positive'). SCI = traumatic spinal cord injury. CP = cerebral palsy

\begin{tabular}{|c|c|c|c|c|c|c|}
\hline \multirow[b]{2}{*}{ Situation } & \multicolumn{6}{|c|}{ Body image } \\
\hline & $\begin{array}{c}\text { SCI } \\
\text { Mean }\end{array}$ & $\begin{array}{c}(\mathrm{n}=10) \\
\text { Range }\end{array}$ & $\begin{array}{c}\text { CP } \\
\text { Mean }\end{array}$ & $\begin{array}{c}(\mathrm{n}=12) \\
\text { Range }\end{array}$ & $\begin{array}{l}\text { Non- } \\
\text { disabled } \\
\text { Mean }\end{array}$ & $\begin{array}{c}(\mathrm{n}=43) \\
\text { Range }\end{array}$ \\
\hline Being downtown & $57 \cdot 5$ & $19-92$ & $52 \cdot 3$ & $27-96$ & $54 \cdot 7$ & $22-89$ \\
\hline Being outdoors (countryside) & $42 \cdot 0$ & $4-100$ & $57 \cdot 8$ & $36-86$ & $77 \cdot 2$ & $43-100$ \\
\hline Waking up & $52 \cdot 0$ & $1-90$ & $49 \cdot 6$ & $7-92$ & $51 \cdot 0$ & $10-92$ \\
\hline Taking a shower & $70 \cdot 9$ & $15-93$ & $55 \cdot 4^{\star}$ & $21-89$ & $69 \cdot 9$ & $23-98$ \\
\hline After a meal (just enough food) & $55 \cdot 2$ & $18-89$ & $66 \cdot 8$ & $44-94$ & $69 \cdot 3$ & $26-97$ \\
\hline Looking in a full-length mirror & $47 \cdot 8$ & $15-88$ & $54 \cdot 3$ & $19-91$ & $48 \cdot 5$ & $12-86$ \\
\hline Having a full-length photo taken & $50 \cdot 3$ & $0-98$ & $47 \cdot 3$ & $9-91$ & $42 \cdot 4$ & $5-75$ \\
\hline Body image as a whole & $57 \cdot 2$ & $11-100$ & $53 \cdot 9$ & $42-76$ & $58 \cdot 4$ & $32-88$ \\
\hline
\end{tabular}

$\star_{n}=11$. For one woman with cerebral palsy, the situation of taking a shower changed greatly depending on who was assisting her.

made on pre-fixed locations. An index was calculated as the estimated values divided by the real measurements on the interviewed person.

\section{Results}

The experiences of the body in different circumstances, marked on a visual analogue scale between 'extremely negative' and 'extremely positive', are presented in Table II. Most frequently the experiences were marked around the middle of the scale, both by the persons with disability and by the reference group. The lowest mean values were found for the body image of persons with traumatic SCI when being outdoors (countryside). High values were noted for the persons with SCI concerning the body image when taking a shower and for the persons with CP after a meal (just enough food). The highest mean value was recorded for the non-disabled persons' estimation of their body image when being outdoors (countryside). In Table II the values of the body image 'as a whole' are also presented, and the findings for these are similar to the results given above.

The results of the Body Puzzle are presented in Table III and Figure 1. The widths of the head, arms and legs were overestimated by the groups with traumatic SCI and CP, and also-to a lesser degree-by the non-disabled reference group.

From the body weight and height, the body mass index $(\mathrm{BMI}=$ weight $(\mathrm{kg}) /$ height $(\mathrm{m})^{2}$ was calculated. The individual indices are shown in Figure 2, where 
Table III The ratios between sizes of different body parts self-estimated with use of a Body Puzzle and actual measurements in 10 persons with traumatic spinal cord injury (SCI), 12 with cerebral palsy (CP) and 43 non-disabled (ND) persons. High ratio = overestimation

\begin{tabular}{llccccc}
\hline & Head & $\begin{array}{c}\text { Upper } \\
\text { Trunk }\end{array}$ & Arms & $\begin{array}{c}\text { Lower } \\
\text { Trunk }\end{array}$ & $\begin{array}{c}\text { Legs } \\
\text { (lower part) }\end{array}$ \\
\hline SCI & Male & 1.46 & 1.09 & 1.61 & 1.21 & 1.43 \\
& Female & 1.17 & 0.96 & 1.58 & 0.97 & 1.36 \\
CP & Male & 1.41 & 1.16 & 1.65 & 1.16 & 1.53 \\
& Female & 1.36 & 0.97 & 1.78 & 1.11 & 1.60 \\
ND & Male & 1.29 & 1.00 & 1.30 & 1.01 & 1.07 \\
& Female & 1.24 & 1.01 & 1.34 & 0.98 & 1.05 \\
\hline
\end{tabular}

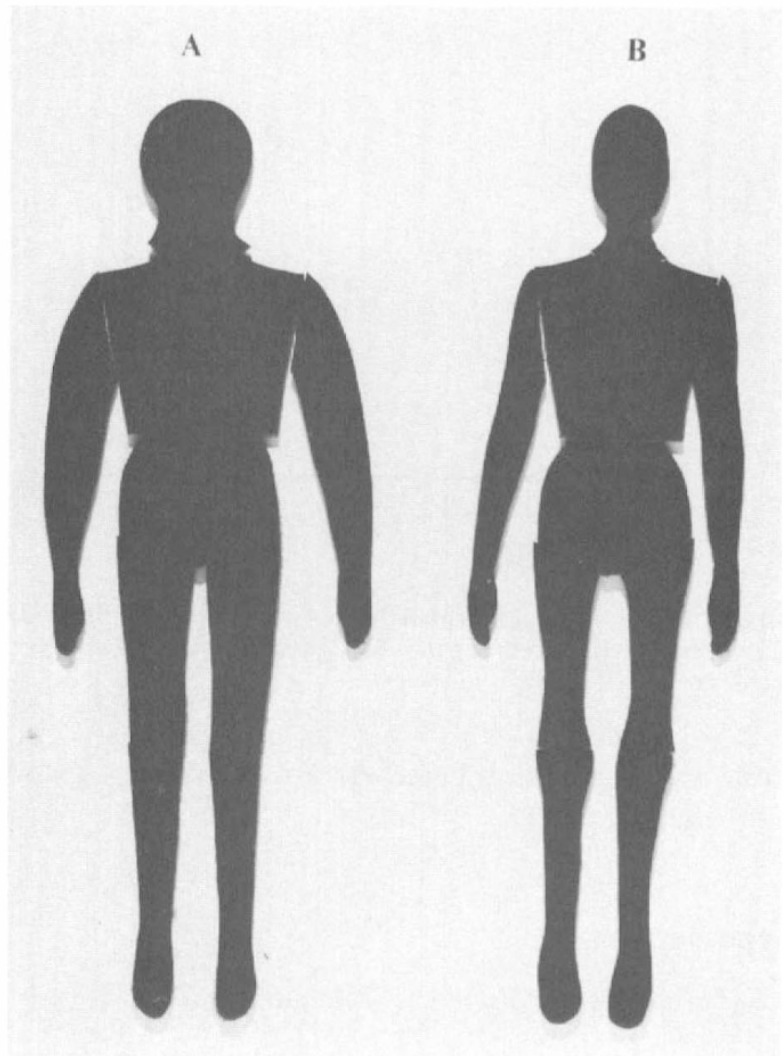

Figure 1 A male person with SCI estimated his body proportions in a Body Puzzle test and presented model A. His real body proportions are presented in model B, prepared from real measurements on pre-fixed locations. 


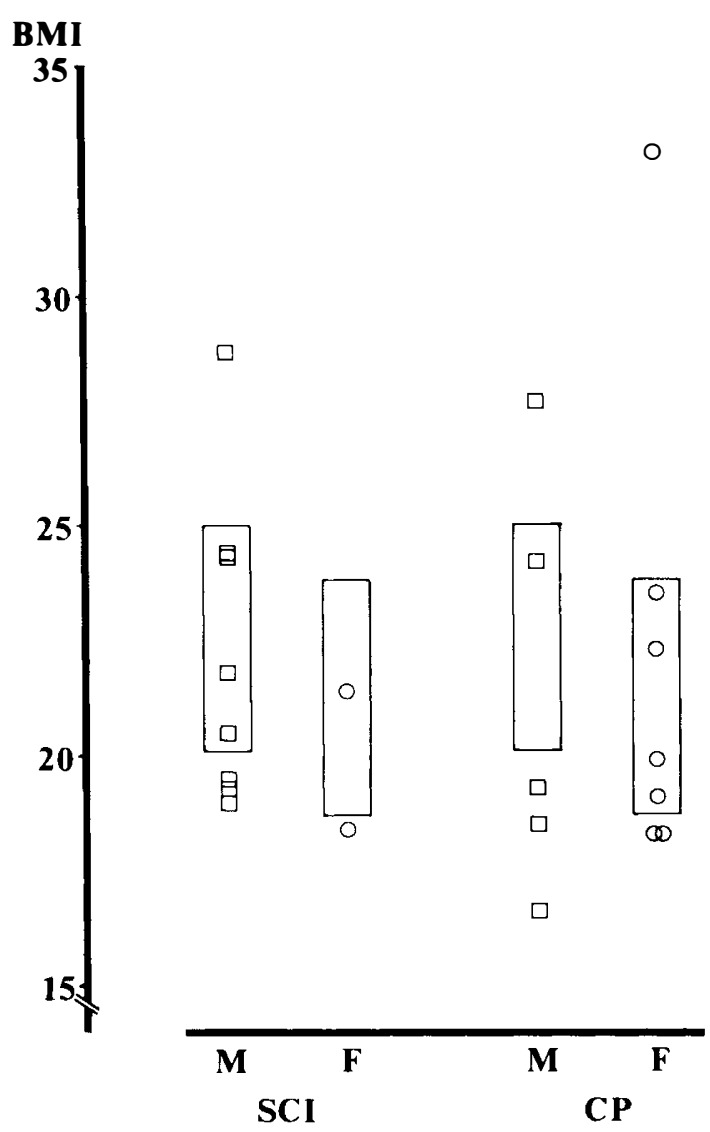

Figure 2 Body Mass Index $\left(\mathrm{BMI}=\right.$ weight $\left.(\mathrm{kg}) / \mathrm{height}(\mathrm{m})^{2}\right)$ of 10 persons with traumatic spinal cord injury (SCI) and 12 persons with cerebral palsy $(\mathrm{CP})$. Acceptable weight ranges are marked with frames for males $(\mathbf{M})$ and females $(\mathbf{F})$.

suggested acceptable ranges are indicated (from the report on obesity of the Royal College of Physicians, 1983).

\section{Some specific experiences}

From the viewpoint of a wheelchair user- 'wheelchair level'

This was not a major problem for any of the 22 interviewed persons. Some wellknown negative experiences were reported. Most common was talking over one's head, when for example sales clerks address a non-handicapped accompanying person, instead of the person in the wheelchair. This situation can be avoided if the person with the severe motor impairment initiates the conversation. The wheelchair level is compensated by good eye-contact. The possibility of mechanically raising the seat of the wheelchair was described as positive by the persons who had had a chance to try. For a non-disabled person to sit on his heels for conversation was regarded on the whole as negative and 'artificial' by 
the SCI and CP groups. In crowds the predominant site of people's backs could be frustrating. Several persons reported difficulties in judging the height of nondisabled persons.

\section{Body language}

There were four main problems. The first one was difficulty in expressing anger-putting one's foot down. The second one was inability to embrace, especially small children. Thirdly, most of the interviewed persons had difficulty in describing small and large things with their arms and hands. A fourth problem was in shaking hands, which mainly arose because of doubtfulness of nondisabled persons. Persons with SCI reported that their hands were touched as if they were fragile. This was mostly experienced as positive, since some of them were afraid that they could be pulled over by the hand-shaking. The importance of initial verbal information to the person met was stressed by the persons with disability. On the whole, these problems were not of great importance to them.

\section{Sex role}

Only 2 persons reported any influence on their male or female image. One young man with CP said that he felt a need to stress that he was a man in spite of his disability. Another young man with SCI mentioned difficulties in being accepted as a man among men, but this improved when he started to drive his car again. Some of the interviewed persons felt sad that they were unable to dance.

\section{Moving about in dreams}

Most of the persons in both groups dreamt that they were moving around in their wheelchair, but also that they were walking or running. Even dancing was reported by a woman with CP. A young woman with SCI stated that in her dreams, when faced with a hindrance, she took her wheelchair on her back. Many persons with SCI reported that after the injury they walked more slowly and stumbled in their dreams. This was also the case in a young man who was slalom skiing in his dreams in a less skilful way.

\section{Contractures}

These were reported by half of the total group. They were less common among the ten persons with traumatic SCI, two of whom reported this symptom, and only in one of them did the contractures give rise to practical problems. Eight out of 12 persons with CP reported contractures, and these caused minor practical problems in 5 of the 8 .

\section{Sensations from the body below the lesion}

None of the persons with SCI had had frightening sensations that the body parts below the injury were in different positions. Of course they did not 
experience the position of the paralysed body parts, this was corrected by the sight. Severe pain, mostly of a phantom character, was reported by 5 of the 10 persons with traumatic SCI.

\section{Other comments}

Unintentional hitting of other persons was sometimes a problem among persons with CP and athetosis. One of them reported how up till the age of 20 he called his arms 'the bandits', and experienced them as if they did not belong to his body. Slobbering represented a problem to those persons with CP who had this symptom.

The importance of sport for the disabled has been emphasised by Guttmann (1976). Six out of 10 persons with traumatic SCI had some form of regular exercise. One of them took part in exercises for the disabled regularly and three sporadically. Among the persons with $\mathrm{CP}, 4$ had regular exercise, one in the form of sports for the disabled.

The four most common answers to the question of how to improve a less good body image were: ordinary training, sports for the disabled, being out together with non-disabled persons, and increasing self-confidence. The importance of nice-looking clothes was also stressed.

\section{Discussion}

The 22 interviewed persons are representative of the groups with acquired and congenital disability in Sweden. All subjects were wheelchair users in need of daily assistance from another person. None of them had another severe disability not associated with the impairment of mobility. Only $12^{\circ}$ o declined to be interviewed. The methods were by necessity based on subjective data, since the body image is an individual experience. The advantages and disadvantages of using subjective data are well known (Feinstein, 1983), but this way of obtaining information is being used increasingly in different medical sciences. No problems in this respect were disclosed during the 22 interviews.

The satisfaction/dissatisfaction with the body, both in neutral and in provocative situations, did not differ from that among non-disabled reference subjects. Essentially no differences were found between persons with tetraplegia and those with cerebral palsy concerning body image. It is my clinical experience that there are differences in psychosocial adjustment between the two groups and further investigation on this topic would be of great value. Subjective assessment of the body proportion as compared with the real size showed in both groups an overestimation of the size of the head, arms and legs, but this was also the case among the non-disabled reference persons for the head and arms, to a lesser degree. This adaptation to the changed body is in accordance with the adjustment to disability described by Wright (1960), Bracken and Shepard (1980), Ray and West (1984) and Stensman (1985).

The mean body mass indices in both disabled groups showed no tendency towards either high or low values compared with the recommended index, but the number of persons studied is too small to draw any conclusion from this finding. 
The experiences regarding different situations related to the body ("wheel chair position', body language, sex role etc.) did not on the whole represent any relevant problems. This contrasted to the highly negative description of problems related to both balance and pain among the persons with SCI.

It is not unusual for people around the disabled person to regard the changed body as something negative. This 'pitying' mentality will hopefully be replaced by more 'normal' attitudes towards the persons with severe mobility impairment in the future. Athletic activities-individual and team sports for physically disabled persons-offer a three-fold bonus through improved physical fitness, increased self-confidence and fellowship. 'Living a normal life creates opportunities to accept the body' was the most common statement among the interviewed persons.

\section{Acknowledgement}

Support for this work was provided by the Royal Wedding Fund in Sweden and the Swedish Association for Traffic and Polio Injured.

\section{References}

ARNhOFF FN, MEHL MC 1963 Body image deterioration in paraplegia. Fournal of Nervous and Mental Disease 137:88-92.

Bors E 1951 Phantom limbs of patients with spinal cord injury. American Medical Association Archives of Neurological Psychiatry 66:610-631.

BRACKEN MB, ShEPARD MJ 1980 Coping and adaption following acute spinal cord injury: A theoretical analysis. Paraplegia 18:74-85.

CoNOMY JP 1973 Disorders of body image after spinal cord injury. Neurology 23:842-50.

EvaNS JH 1962 On disturbance of the body image in paraplegia. Brain 85:687-700.

FEINSTEIN AR 1983 An additional basic science for clincal medicine: IV. The development of clinimetrics. Annals of Internal Medicine 99:843-848.

Fisher S, Cleveland SE 1958 Body image and personality, D van Nostrand Co Inc, New Jersey, USA.

Guttmann L 1976 Textbook of Sport for the Disabled. Alden Press, Oxford.

Katz S, Ford AB, Moskowitz RW, et al. 1963 Studies of illness in the aged; The Index of ADL: A standardized measure of biological and psychosocial function. Fournal of the American Medical Association 185:914-919.

MitChELL KR 1970 The body image barrier variable and level of adjustment to stress induced by severe physical disability. Fournal of Clinical Psychology 26:49-52.

Obesity: a report of the Royal College of Physicians 1983. Fournal of the Royal College of Physicians London 17:3-58.

Ray C, West J 1984 II Coping with spinal cord injury. Paraplegia 22:249-259.

Rosillo RH, Fogel ML 1971 Correlation of pschologic variables and progress in physical rehabilitation: IV The relation of body image to success in physical rehabilitation. Archives of Physical Medicine and Rehabilitation 52:182-186.

SCHILDER P 1935 Image and Appearance of the Human Body. Kegan Paul, Trench \& Trubner, London.

STENSMAN R 1985 Severe mobility-disabled people assess the quality of their lives. Scandinavian Fournal of Rehabilitation Medicine 17:87-99.

TRIESChMANN RB 1980 Spinal cord injuries: Psychological, social and vocational adjustment, Pergamon Press, New York pp 65-67.

WaCHS H, ZaKs MS 1960 Studies of body image in men with spinal cord injury. Fournal of Nervous and Mental Disease 131:121-127.

VAN DER WELDE CD 1985 Body images of one's self and of others: Development and clinical significance. American Fournal of Psychiatry 142:527-537.

WRIGHT BA 1960 Physical Disability-A Psychological Approach, Harper, New York. 